This item was submitted to Loughborough's Research Repository by the author.

Items in Figshare are protected by copyright, with all rights reserved, unless otherwise indicated.

\title{
Perceived exertion responses to wheelchair propulsion differ between novice able-bodied and trained wheelchair sportspeople
}

PLEASE CITE THE PUBLISHED VERSION

https://doi.org/10.1016/j.jsams.2019.10.012

\section{PUBLISHER}

Elsevier

VERSION

AM (Accepted Manuscript)

\section{PUBLISHER STATEMENT}

This paper was accepted for publication in the journal Journal of Science and Medicine in Sport and the definitive published version is available at https://doi.org/10.1016/j.jsams.2019.10.012.

\section{LICENCE}

CC BY-NC-ND 4.0

\section{REPOSITORY RECORD}

Hutchinson, Michael, Jonathan Kilgallon, Christof Leicht, and Vicky Goosey-Tolfrey. 2019. "Perceived Exertion Responses to Wheelchair Propulsion Differ Between Novice Able-bodied and Trained Wheelchair Sportspeople". Loughborough University. https://hdl.handle.net/2134/9987935.v1. 
Objectives: To investigate peripheral $\left(\mathrm{RPE}_{\mathrm{P}}\right)$ and central $\left(\mathrm{RPE}_{\mathrm{C}}\right)$ rating of perceived exertion during

3 wheelchair propulsion in untrained able-bodied $(\mathrm{AB})$ participants, and trained wheelchair rugby athletes

$4 \quad$ with and without cervical spinal cord injury (CSCI).

Design: Cross-sectional study.

Methods: 38 participants (AB: $\mathrm{n}=20$; wheelchair rugby athletes with CSCI: $\mathrm{n}=9$; without CSCI: $\mathrm{n}=$

9) completed an incremental wheelchair propulsion test to exhaustion on a motorised treadmill. Gas exchange measures and heart rate (HR) were collected throughout. $\mathrm{RPE}_{\mathrm{P}}$ and $\mathrm{RPE} \mathrm{E}_{\mathrm{C}}$ on the Category

9 Ratio-10 were verbally recorded each minute. Blood lactate concentration ([BLa]) was determined post10 test.

11 Results: Between 50-100\% peak oxygen uptake $\left(\dot{\mathrm{V}} \mathrm{O}_{2 \text { peak }}\right)$, $\mathrm{RPE}_{\mathrm{P}}$ was greater than $\mathrm{RPE}_{\mathrm{C}}$ in $\mathrm{AB}(\mathrm{p}<0.05)$, 12 but not in athletes with $(\mathrm{p}=0.07)$ or without $(\mathrm{p}=0.16)$ CSCI. RPE $\mathrm{P}$ was greater in AB compared to 13 players with CSCI (Effect sizes: 1.24-1.62), as were respiratory exchange ratio (1.02 \pm 0.10 vs. $0.82 \pm$ $140.11, \mathrm{p}<0.05)$ and $[\mathrm{BLa}]_{\text {peak }}\left(7.98 \pm 2.53 \mathrm{vs} 4.66 \pm 1.57 \mathrm{mmol} \cdot \mathrm{L}^{-1}\right) . \mathrm{RPE}_{\mathrm{C}}$ was greater in athletes without 15 CSCI compared to those with CSCI (Effect sizes: 0.70-1.38), as were HR (166 \pm 20 vs. $104 \pm 15$ 16 beats $\left.\cdot \min ^{-1}, \mathrm{p}<0.05\right)$ and ventilation $\left(59.2 \pm 28.8\right.$ vs. $\left.35.1 \pm 16.6 \mathrm{~L} \cdot \mathrm{min}^{-1}, \mathrm{p}=0.01\right)$.

17 Conclusion: $\mathrm{RPEP}$ was dominant over $\mathrm{RPE}_{\mathrm{C}}$ during wheelchair propulsion for untrained $\mathrm{AB}$ participants.

18 For athletes with CSCI, lower $\mathrm{RPE}_{\mathrm{P}}$ and $\mathrm{RPE}_{\mathrm{C}}$ were reported at the same $\% \dot{\mathrm{VO}}_{2 \text { peak }}$ compared to those 19 without CSCI. The mechanism for this remains to be fully elucidated.

20 Key Words: differentiated, perceived exertion, tetraplegia, afferent feedback, central drive 


\section{Introduction}

The purpose of population-specific exercise guidelines is to describe the duration, frequency, and intensity of exercise necessary for improving fitness and health. ${ }^{1}$ For adults with a spinal cord injury (SCI) the exercise guidelines recommend engaging in at least 20 min aerobic exercise, twice weekly, at a moderate to vigorous intensity. ${ }^{2,3}$ That said, though objective markers such as oxygen uptake $\left(\dot{\mathrm{V}}_{2}\right)$ and heart rate (HR) are preferred for prescribing exercise intensity, ${ }^{4}$ the ease of application of Ratings of Perceived Exertion (RPE) offers an enticing alternative. However, a recent systematic review concluded that there is insufficient evidence regarding the reliable and valid use of RPE to regulate exercise intensity in adults with SCI, due to a lack of consistent results from high quality studies. ${ }^{5}$ As such, more evidence is required to understand RPE responses in persons with SCI in order to inform its use for exercise prescription.

Van der Scheer et al. ${ }^{5}$ highlighted how greater understanding is needed over the use of differentiated RPE in adults with SCI, as opposed to a whole-body, overall rating of RPE (RPEO). When differentiating RPE, participants can report a peripheral $R P E\left(R_{P E}\right)$, based on the exertion of the active muscles, and central RPE (RPE $)$ based on cardiorespiratory cues. ${ }^{6}$ For upper body exercise (the modality commonly used by persons with $\mathrm{SCI}$ ), where the musculature is typically smaller, it may be that exertional cues from the periphery are different to those from the cardiorespiratory system. ${ }^{7,8}$ Trained wheelchair rugby players with cervical SCI (CSCI) show no difference in the relationships between $\mathrm{RPE}_{\mathrm{O}}, \mathrm{RPE}_{\mathrm{P}}$, or $\mathrm{RPE}_{\mathrm{C}}$, and $\dot{\mathrm{V}}_{2}$, or the differentiated $\mathrm{RPE}$ at peak oxygen uptake $\left(\dot{\mathrm{V}}_{2 \text { peak }}\right){ }^{9}$ Conversely, a recent study showed that $\mathrm{RPE}_{\mathrm{P}}$ increases significantly faster than $\mathrm{RPE}_{\mathrm{C}}$ during incremental arm crank ergometry in untrained people with CSCI. ${ }^{8}$ These divergent findings in CSCI suggest a potential role of training status in the differentiated RPE response to upper body exercise. Understanding the $\mathrm{RPE}_{\mathrm{P}}$ and $\mathrm{RPE}_{\mathrm{C}}$ responses to exercise in untrained $\mathrm{AB}$ and trained people with, and without, CSCI will aid the implementation of exercise training programmes with differentiated RPE in these populations. 
Athletes eligible for classification in wheelchair rugby include those with CSCI, and other forms of disability. These players without CSCI, like $\mathrm{AB}$, have unimpaired afferent feedback from the upper body to the brain. However, for players with a complete CSCI the number of afferent signals informing the brain via neural pathways will be inversely related to lesion level. Group III and IV afferents with receptors located within skeletal muscle respond to mechanical and chemical stimuli induced by muscle contraction and contribute to the autonomic control of cardiovascular and ventilatory responses to exercise,${ }^{10}$ and have been implicated in the generation of RPE. ${ }^{11}$ Sympathetic innervation of the heart, intercostal and abdominal muscles arise from the thoracic region of the spinal cord, ${ }^{12}$ leading to blunted peak $\mathrm{HR}\left(\mathrm{HR}_{\text {peak }}\right)^{13}$ and limiting inspiratory and expiratory efforts during exercise ${ }^{12,14,15}$ in complete CSCI. It is hence possible that injury-dependent consequences also impact the RPE reported by people with CSCI during exercise. Comparing the physiological and differentiated RPE responses to exercise between $\mathrm{AB}$ and wheelchair rugby players with and without CSCI may help elucidate the mechanisms involved in generating RPE.

As such, the primary aim of this study was to investigate the effect of training status on the differentiated RPE response to incremental exercise by comparing responses in $\mathrm{AB}$ and trained athletes with CSCI. It was hypothesised that RPE $\mathrm{P}_{\mathrm{P}}$ would increase significantly faster than $\mathrm{RPE}_{\mathrm{C}}$ with increasing exercise intensity in $\mathrm{AB}$, but not trained wheelchair rugby athletes. A secondary aim was to investigate the role of CSCI on RPE responses.

\section{Methods}

Thirty-eight healthy adults who provided written, informed consent, volunteered to take part in the study, which was approved by the Loughborough University Ethics Human Participants Subcommittee (R17-P130). The sample comprised three subgroups: AB $(n=20 ; 22 \pm 2$ years; $86.7 \pm 14.4$ $\mathrm{kg})$; and experienced wheelchair rugby players with complete CSCI (CSCI; $\mathrm{n}=9 ; 29 \pm 7$ years; $68.9 \pm$ $12.4 \mathrm{~kg}$ ), or a disability other than CSCI (Non-SCI; $\mathrm{n}=9 ; 28 \pm 5$ years; $60.1 \pm 12.8 \mathrm{~kg}$ ). All participants were male except for one female participant with CSCI. AB participants were untrained in upper body aerobic exercise but were habitually trained and competing at a university sport level. The Non-SCI 
group included participants with amputation $(n=4)$, arthrogryposis, cerebral palsy, osteogenesis imperfecta, polyneuropathy, and Roberts syndrome (all $n=1$ ), thus having no paralysis of the upper body and trunk.

Participants completed a single trial consisting of submaximal and maximal wheelchair propulsion tests on a motorised treadmill (HP Cosmos, Traunstein, Germany). AB participants completed two prior trials to familiarise them with WCP. Familiarisation was not needed for the athletes given their training status and that all were manual wheelchair users. Familiarisation and main trials were separated by a minimum of 2 , and maximum of 5 days.

The first familiarisation trial consisted of a $10 \mathrm{~min}$ period at $1.0-1.2 \mathrm{~m} \cdot \mathrm{s}^{-1}$ with participants free to experiment and find a propulsion technique they were comfortable with. No training was given, however participants were encouraged to vary their push frequency and contact angle with the push rim until finding a preferable combination. ${ }^{16}$ Following this, $\mathrm{AB}$ performed two, 3 min blocks at 1.4 and 1.6 $\mathrm{m} \cdot \mathrm{s}^{-1}$. The second familiarisation trial exposed participants to maximal intensity wheelchair propulsion and utilised the same protocol as the main trial, including all measures.

Following a self-selected warm up, participants completed a submaximal test comprising six to eight, discontinuous, 3 min stages. Starting speed was between 1.0 and $2.2 \mathrm{~m} \cdot \mathrm{s}^{-1}$, depending on experience and level of physical function, and was increased by $0.2 \mathrm{~m} \cdot \mathrm{s}^{-1}$ in AB and CSCI, and by 0.3 $\mathrm{m} \cdot \mathrm{s}^{-1}$ in Non-SCI. Oxygen uptake $\left(\dot{\mathrm{VO}}_{2}\right)$, minute ventilation $(\dot{\mathrm{V} E})$ and respiratory exchange ratio (RER) via online gas analysis (Metalyzer 3B, Cortex, Leipzig, Germany) and HR (RS400, Polar, Kempele, Finland) were collected throughout. At the end of each stage treadmill speed was reduced to allow a capillary blood sample to be taken from the earlobe for measurement of blood lactate concentration ([BLa]) using Biosen C-line monitor (EKF diagnostics, Barleben, Germany). Once the sample had been obtained (30-45 s) the next stage commenced. The test was terminated once [BLa] exceeded $4 \mathrm{mmol} \cdot \mathrm{L}^{-}$ 1.

Participants then received $15 \mathrm{~min}$ of active recovery and/or rest before performing a graded exercise test $\left(1.2-3.2 \mathrm{~m} \cdot \mathrm{s}^{-1}+0.1 \mathrm{~m} \cdot \mathrm{s}^{-1} \cdot \mathrm{min}^{-1}\right)$ to volitional exhaustion. Starting speed was set to the speed 
from the submaximal test where [BLa] increased $\left(\sim 0.5 \mathrm{mmol} \cdot \mathrm{L}^{-1}\right)$ above the resting value. Gas exchange variables and HR were collected throughout, with [BLa] determined immediately post-test. RPEP and $\mathrm{RPE}_{\mathrm{C}}$ were verbally reported at the end of each minute throughout, as well as at termination of the test on the CR-10 scale. ${ }^{17}$ Participants were instructed to focus on how hard and strenuous the task felt in the working musculature $\left(\mathrm{RPE}_{\mathrm{P}}\right)$ and cardiorespiratory systems $\left(\mathrm{RPE}_{\mathrm{C}}\right)$, and not on any sensations of pain or discomfort. ${ }^{6,18}$

Statistical analyses were performed using IBM SPSS Statistics 23 (SPSS Inc., Chicago, IL.). Data are presented as mean $\pm \mathrm{SD}$, with statistical significance accepted at $\mathrm{p}<0.05$. Data were checked for normal distribution using the Shapiro Wilk statistic. Differences in peak responses between AB, Non-SCI and CSCI were assessed by one-way analysis of variance (ANOVA) with Bonferroni post-hoc for multiple comparisons. The Greenhouse-Geisser epsilon was used unless it was greater than 0.75 , in which case the Huynh-Feldt epsilon was used.

$\mathrm{RPE}_{\mathrm{P}}$ and $\mathrm{RPE}_{\mathrm{C}}$ were fit using a quadratic function against normalised test duration and exercise intensity $\left(\% \dot{\mathrm{VO}}_{2 \text { peak }}\right) .{ }^{8}$ The $\mathrm{RPE}_{\mathrm{P}}$ and $\mathrm{RPE}_{\mathrm{C}}$ corresponding to $10 \%$ intervals for the entire test duration and from 50 to $100 \% \dot{\mathrm{VO}}_{2 \text { peak }}$ were then calculated. Three-way repeated measures ANOVA were used to assess the effect of RPE differential, group, and time or $\% \dot{\mathrm{V}} \mathrm{O}_{2 \text { peak. }}$ In the event of a significant interaction effect involving the group factor, separate two-way repeated measures ANOVA, with Bonferroni post-hoc, were used to assess differences in $\mathrm{RPE}_{\mathrm{P}}$ and $\mathrm{RPE} \mathrm{E}_{\mathrm{C}}$ within subgroups. For the RPE values modelled against time these were $2\left(\mathrm{RPE}_{\mathrm{P}}, \mathrm{RPE}_{\mathrm{C}}\right)$ × $10(10-100 \%$ test duration) ANOVA, and for the values modelled against $\dot{\mathrm{V}} \mathrm{O}_{2 \text { peak }}$ were $2\left(\mathrm{RPE}_{\mathrm{P}}, \mathrm{RPE}_{\mathrm{C}}\right)$ x $6\left(50-100 \% \dot{\mathrm{VO}}_{2 \text { peak }}\right)$ ANOVA. In each case the Cohen's effect sizes (ES) and 90\% confidence interval ${ }^{19}$ were calculated for RPEP and RPE between subgroups from $50-100 \% \dot{\mathrm{V}}_{2 \text { peak }}$ and categorised as trivial $(<0.2)$, small $(0.2-0.6)$, moderate $(0.6-1.2)$, large (1.2-2.0) and very large $(>2.0) .^{20}$

RER, $\dot{V} E$ and $\mathrm{HR}$ were fit against $\% \dot{\mathrm{V}} \mathrm{O}_{2 \text { peak }}$ using a linear function, with values extracted corresponding to $10 \%$ intervals from $50-100 \% \dot{\mathrm{V}}_{2 \text { peak. }}$. Differences between subgroups were assessed 
using 2 x 6 mixed model ANOVA with the between measure being "group" and the within measure

124 being "نंO 2 peak".

\section{Results}

Maximal responses to incremental wheelchair propulsion are presented in Table 1. Absolute

$127 \dot{\mathrm{V}} \mathrm{O}_{2 \text { peak }}$ was greater in $\mathrm{AB}$ compared to Non-SCI (mean difference, 95\% confidence interval: 0.6, 0.1-

$\left.1281.2 \mathrm{~L} \cdot \mathrm{min}^{-1}, \mathrm{p}=0.03\right)$ and CSCI $\left(1.6,1.0-2.2 \mathrm{~L} \cdot \mathrm{min}^{-1}, \mathrm{p}<0.005\right)$, as well as Non-SCI compared to CSCI

$129\left(1.0,0.3-1.6 \mathrm{~L} \cdot \mathrm{min}^{-1}, \mathrm{p}=0.01\right)$. Relative $\dot{\mathrm{V}} \mathrm{O}_{2 \text { peak }}$ was greater in $\mathrm{AB}\left(14.3,8.5-20.2 \mathrm{ml} \cdot \mathrm{kg}^{-1} \cdot \mathrm{min}^{1}, \mathrm{p}<\right.$

130 0.005) and Non-SCI $\left(18.8,1.9-25.7 \mathrm{ml} \cdot \mathrm{kg}^{-1} \cdot \mathrm{min}^{1}, \mathrm{p}<0.005\right)$ than CSCI. HR peak was greater in AB

131 compared to CSCI $\left(56,40-72\right.$ beats $\left.\cdot \min ^{-1}, \mathrm{p}<0.005\right)$, but also Non-SCI compared to AB $(16,2-30$

132 beats $\left.\cdot \min ^{-1}, \mathrm{p}=0.03\right)$ and $\operatorname{CSCI}\left(72,54-90\right.$ beats $\left.\cdot \min ^{-1}, \mathrm{p}<0.005\right)$. Peak [BLa] was significantly greater

133 in $\mathrm{AB}\left(3.31,1.04-5.60 \mathrm{mmol} \cdot \mathrm{L}^{-1}, \mathrm{p}<0.005\right)$ and Non-SCI $\left(4.03,1.40-6.66 \mathrm{mmol} \cdot \mathrm{L}^{-1}, \mathrm{p}<0.005\right)$ than

134 in CSCI $\left(4.66 \pm 1.57 \mathrm{mmol} \cdot \mathrm{L}^{-1}\right)$. Peak propulsion speed was significantly greater in Non-SCI than AB

$135\left(0.8,0.4-1.2 \mathrm{~m} \cdot \mathrm{s}^{-1}, \mathrm{p}<0.005\right)$ and CSCI $\left(1.1,0.6-1.6 \mathrm{~m} \cdot \mathrm{s}^{-1}, \mathrm{p}<0.005\right)$.

There was a significant interaction between differentiated RPE, normalised test duration and

137 group $(\mathrm{p}<0.005)$. In $\mathrm{AB}$ there was a significant main effect of RPE differential $\left(\mathrm{F}_{(1.00)}=55.14, \mathrm{p}<\right.$

138 0.005) and RPE-time interaction $\left(\mathrm{F}_{(1.83)}=27.99, \mathrm{p}<0.005\right)$. Bonferroni post-hoc tests showed RPE $\mathrm{P}_{\mathrm{P}}$ was

139 significantly greater than $\mathrm{RPE}_{\mathrm{C}}(5.1 \pm 3.0$ vs $3.4 \pm 2.5)$, with $\mathrm{RPE}$ developed quicker than $\mathrm{RPE}_{\mathrm{C}}$ (Figure

140 1a). In Non-SCI and CSCI there was no main effect of RPE differential $\left(\mathrm{F}_{(1.00)}<4.81, \mathrm{p}>0.06\right)$ or RPE-

141 time interaction $\left(\mathrm{F}_{(<1.49)}<2.24, \mathrm{p}>0.16\right.$, Figure $\left.1 \mathrm{~b}, \mathrm{c}\right)$.

142 There was also a significant interaction between differentiated RPE, $\% \dot{\mathrm{V}} \mathrm{O}_{2 \text { peak }}$ and group $(\mathrm{p}<$ 143 0.005). In $A B$ there was a significant main effect of RPE differential $\left(F_{(1.00)}=59.40, p<0.005\right)$ and

$144 \mathrm{RPE}-\% \dot{\mathrm{V}}_{2 \text { peak }}$ interaction $\left(\mathrm{F}_{(1.28)}=12.63, \mathrm{p}=0.01\right)$. Bonferroni post-hoc showed $\mathrm{RPE}_{\mathrm{P}}$ was significantly 145 greater than $\mathrm{RPE}_{\mathrm{C}}(6.6 \pm 2.8$ vs $4.5 \pm 2.5)$, whilst $\mathrm{RPE}_{\mathrm{P}}$ developed significantly faster than $\mathrm{RPE}_{\mathrm{C}}$ (Figure 146 1d). In Non-SCI and CSCI there was no effect of RPE differential $\left(\mathrm{F}_{(1.00)}<4.25, \mathrm{p}>0.07\right)$ or $147 \mathrm{RPE}-\% \dot{\mathrm{V}} \mathrm{O}_{2 \text { peak }}$ interaction $\left(\mathrm{F}_{(<1.50)}<4.03, \mathrm{p}>0.06\right.$, Figure 1e,f). The ES comparing the difference in $148 \mathrm{RPE}$ and $\mathrm{RPE}_{\mathrm{C}}$ between subgroups at $50-100 \% \dot{\mathrm{V}}_{2 \text { peak }}$ are presented in Figure 2 . The $\mathrm{RPE}$ in $\mathrm{AB}$ was 
greater than CSCI with a large ES, whilst $\mathrm{RPE}_{\mathrm{C}}$ was greater in Non-SCI compared to CSCI with a moderate to large ES.

$\left.152 \pm 0.11 ; 0.20,0.15-0.25 ; \mathrm{F}_{(1.00)}=56.42, \mathrm{p}<0.005 ; \mathrm{ES}=1.87\right)$, though there was no difference in 153 propulsion speed $\left(\mathrm{F}_{(1.00)}=3.68, \mathrm{p}=0.07\right)$. The HR was greater in Non-SCI $\left(166 \pm 20\right.$ beats $\left.\cdot \mathrm{min}^{-1}\right)$ 154 compared to $\mathrm{AB}\left(146 \pm 24\right.$ beats $\cdot \min ^{-1} ; 20,9-30$ beats $\left.\cdot \min ^{-1} ; \mathrm{F}_{(1.00)}=14.27, \mathrm{p}=0.01 ; \mathrm{ES}=0.88\right)$ and CSCI $\left(104 \pm 15\right.$ beats $\cdot \min ^{-1} ; 62,52-72$ beats $\left.\cdot \min ^{-1} ; \mathrm{F}_{(1.00)}=181.27, \mathrm{p}<0.005 ; \mathrm{ES}=3.48\right)$ from $50-100 \%$ $156 \dot{\mathrm{V}} \mathrm{O}_{2 \text { peak. }}$. Propulsion speed was also significantly greater in Non-SCI than AB $\left(3.1 \pm 0.6 \mathrm{vs} 2.3 \pm 0.5 \mathrm{~m} \cdot \mathrm{s}^{-}\right.$ $\left.157{ }^{1} ; 0.8,0.4-1.1 \mathrm{~m} \cdot \mathrm{s}^{-1} ; \mathrm{F}_{(1.00)}=21.84, \mathrm{p}<0.005 ; \mathrm{ES}=1.50\right)$. In contrast, $\dot{\mathrm{V} E}$ was significantly greater in 158 AB than in Non-SCI $\left(75.0 \pm 26.0\right.$ vs $59.2 \pm 28.8 \mathrm{~L} \cdot \mathrm{min}^{-1} ; 15.8,3.7-27.9 \mathrm{~L} \cdot \mathrm{min}^{-1} ; \mathrm{F}_{(1.00)}=7.17, \mathrm{p}=0.01$; $159 \mathrm{ES}=0.59)$, though was also greater in Non-SCI than CSCI $\left(59.2 \pm 28.8\right.$ vs $35.1 \pm 16.6 \mathrm{~L} \cdot \mathrm{min}^{-1}$; 24.1 , 7.8-40.5 L $\left.\cdot \mathrm{min}^{-1} ; \mathrm{F}_{(1.00)}=9.77, \mathrm{p}=0.01 ; \mathrm{ES}=1.03\right)$.

\section{Discussion}

This study examined the use of differentiated RPE to provide a thorough insight into the perceptual responses of untrained $\mathrm{AB}$ and trained wheelchair rugby athletes with and without CSCI. The principal finding was that in untrained $A B$ performing incremental wheelchair propulsion, $\mathrm{RPE}_{\mathrm{P}}$ was significantly greater than $\mathrm{RPE}_{\mathrm{C}}$ between 50 and $100 \% \dot{\mathrm{V}}_{2 \text { peak. }}$. This contrasts with trained wheelchair rugby players who exhibited no difference between $\mathrm{RPE}_{\mathrm{P}}$ and $\mathrm{RPE}_{\mathrm{C}}$ between 50 and $100 \% \dot{\mathrm{V}}_{2 \text { peak}}$, irrespective of their disability.

These findings corroborate previous research that has found a perceptual signal dominance of

$169 \mathrm{RPE}_{\mathrm{P}}$ over $\mathrm{RPE}_{\mathrm{C}}$ in untrained $\mathrm{AB}$ persons performing arm crank, ${ }^{21}$ handcycle, ${ }^{22}$ and wheelchair 170 propulsion $^{7,23,24}$ exercise. Similar investigations into the differentiated RPE of CSCI have proven 171 equivocal. In contrast to the present findings, recreationally-active people with CSCI showed accelerated RPE compared to $\mathrm{RPE}_{\mathrm{C}}$ during incremental arm crank ergometry. ${ }^{8}$ This would suggest a role of training status on the differentiated RPE response to exercise in CSCI. Also of note is that

174 wheelchair rugby players without CSCI showed no difference between $\mathrm{RPE}_{\mathrm{P}}$ and $\mathrm{RPE}_{\mathrm{C}}$, whereas 
untrained $\mathrm{AB}$ did. When running, no difference in the $\mathrm{RPE}_{\mathrm{P}}$ or $\mathrm{RPE}_{\mathrm{C}}$ were found between recreationally-

176 active, or trained participants at equal $\% \dot{\mathrm{V}}{ }_{2 \text { peak. }}{ }^{25}$ Furthermore, running training leading to

177 improvements in $\dot{\mathrm{V}} \mathrm{O}_{2 \text { peak }}$ had no impact on the $\mathrm{RPE}$ at equal $\% \dot{\mathrm{VO}}_{2 \text { peak. }}{ }^{26}$ Together these findings suggest

178 that the relationship between differentiated RPE and $\% \dot{\mathrm{V}} \mathrm{O}_{2 \text { peak }}$ differs between lower and upper body

179 exercise, and that it may be more susceptible to change during upper body exercise. It is possible that

180 the change in relationship in RPE is related to an increase in efficiency with prolonged training. ${ }^{27}$ This

181 has important implications for professionals working with individuals with CSCI to design and

182 implement an exercise training programme. For example, when an individual is untrained the

183 differentiated RPE may be a better indicator of exercise intensity, however with training and the

184 diminishing difference between differentiated RPE, the RPE may be suitable.

This is the first study to note that $\mathrm{AB}$, and wheelchair rugby players with and without $\mathrm{CSCI}$ exhibit different $\mathrm{RPE}_{\mathrm{P}}$ and $\mathrm{RPE}_{\mathrm{C}}$ at the same $\% \mathrm{~V}_{2 \text { peak }}$ during wheelchair propulsion. Specifically, $\mathrm{RPE}_{\mathrm{P}}$ was greater in $\mathrm{AB}$, and $\mathrm{RPE}_{\mathrm{C}}$ greater in athletes without CSCI, compared to those with CSCI. The physiological consequences of CSCI make it an interesting experimental model by which to investigate factors involved in generating RPE, particularly with a complete CSCI in which no motor or sensory

190 function is preserved below the level of the injury. A principle contention surrounds whether the 191 generation of RPE is independent, or not, of afferent feedback from the working musculature. ${ }^{18}$ Whilst 192 there is evidence to suggest a role of Group III and IV muscle afferents in generating RPE, ${ }^{11}$ another 193 perspective is that RPE is independent of afferent feedback and instead reflects corollary discharges 194 emanating from pre and/or motor areas of the brain that are simultaneously directed to sensory areas 195 involved in perception. ${ }^{28}$ According to this view, an increase in RPE reflects an increase in motor related 196 cortical potential, an index of central motor command. This is supported by experimental evidence 197 showing increases in both RPE and cortical potentials when fatigued muscles are exercised, ${ }^{29}$ and 198 decreases by the administration of caffeine causing a decrease in the activity of premotor and motor 199 areas of the brain. ${ }^{30}$ The present finding of increased $\mathrm{RPE}_{\mathrm{C}}$ in athletes without, compared to those with, 200 CSCI could support the role of central motor command in generating RPE. Paralysis caused by CSCI 201 leads to impaired sympathetic innervation of cardiac muscle, as well as of intercostal and abdominal 
muscles involved in inspiratory and expiratory efforts. ${ }^{12}$ Along with increased $\mathrm{RPE}_{\mathrm{C}}$, athletes without

203 CSCI had greater HR and $\dot{V}$ E responses than those with CSCI. This could reflect greater central motor 204 command, due to the increased active musculature, thereby leading to the increased $\mathrm{RPE}_{\mathrm{c}}$. However, 205 the increased active musculature could also be generating greater feedback via Group III and IV muscle 206 afferents and be contributing to the increased $R P E_{C}$. As such, further investigations are required to 207 independently assess the role of central motor command in generating RPE.

An alternative hypothesis concerns whether afferent feedback contributes to the generation of RPE. Whereas central motor command appears to exert its effect on RPE independently, ${ }^{29}$ evidence also implicates Group III and IV afferents in the generation of RPE. ${ }^{11}$ In the present study, RPE was 211 increased in $\mathrm{AB}$ compared to wheelchair rugby players with CSCI from $50-100 \% \mathrm{~V}_{2}$ peak with large ES,

212 despite no difference in the propulsion speed. However, not only was RER significantly greater in $A B$ 213 compared to those with $\mathrm{CSCI}$ at the same $\% \mathrm{~V}_{2 \text { peak }}$, post-test $[\mathrm{BLa}]$ was also greater in $\mathrm{AB}$. This 214 apparent increased rate of glycolysis in AB likely led to a greater accumulation of metabolites, and thereby increased afferent feedback and potentially contributing to the higher RPE in $A B$. These results would hence serve to support the hypothesis that afferent feedback does indeed contribute to generating RPE.

\section{Conclusions}

In conclusion, during incremental wheelchair propulsion $\mathrm{RPE}_{\mathrm{P}}$ was significantly greater than $\mathrm{RPE}_{\mathrm{C}}$ in untrained $\mathrm{AB}$, whilst no differences between $\mathrm{RPE}_{\mathrm{P}}$ and $\mathrm{RPE} \mathrm{E}_{\mathrm{C}}$ were found in trained wheelchair rugby players, irrespective of disability. The noted increases in $\mathrm{RPE}_{\mathrm{P}}$ for $\mathrm{AB}$ compared to athletes with CSCI supports a role of afferent feedback in generating RPE.

\section{Practical applications}

- For individuals untrained in upper body exercise, differentiated RPE should be collected to gain a more complete representation of the exertion felt.

- As an individual becomes more trained and the differentiated RPE become more similar, then a single overall RPE may be appropriate. 
- For a practitioner working with an athlete group containing different disabilities, the same RPE prescription will not equate to the same relative intensity for each athlete because of disabilityrelated consequences on the mechanism of the RPE response.

231

232 Acknowledgements

233 The authors thank the participants who volunteered to take part in this study and Tom O'Brien for his

234 help with the data collection. This research did not receive any specific grant from funding agencies in

235 the public, commercial, or not-for-profit sectors.

236 Declarations of interest: none. 


\section{References}

2381 American College of Sports Medicine, Riebe D, Ehrman JK, et al. ACSM's guidelines for

239 exercise testing and prescription. Tenth edit. Philadelphia, PA, Wolters Kluwer, 2018.

2402 Martin Ginis KA, van der Scheer JW, Latimer-Cheung AE, et al. Evidence-based scientific 241 exercise guidelines for adults with spinal cord injury: an update and a new guideline. Spinal Cord 2018; 56(4):308-321. Doi: 10.1038/s41393-017-0017-3.

2433 van der Scheer JW, Martin Ginis KA, Ditor DS, et al. Effects of exercise on fitness and health 244 of adults with spinal cord injury. Neurology 2017; 89(7):736-745. Doi: 10.1212/WNL.0000000000004224.

2464 Garber CE, Blissmer B, Deschenes MR, et al. American College of Sports Medicine Position stand. Quantity and quality of exercise for developing and maintaining cardiorespiratory, musculoskeletal, and neuromotor fitness in apparently healthy adults: guidance for prescribing exercise. Med Sci Sports Exerc 2011; 43(7):1334-1359. Doi: 10.1249/MSS.0b013e318213fefb.

2505 van der Scheer JW, Hutchinson M, Paulson T, et al. Reliability and validity of subjective measures of aerobic intensity in adults with spinal cord injury: a systematic review. $P M \& R$ 2018; 10(2):194-207. Doi: 10.1016/j.pmrj.2017.08.440.

7 Lenton JP, Fowler NE, van der Woude L, et al. Wheelchair propulsion: effects of experience and push strategy on efficiency and perceived exertion. Appl Physiol Nutr Metab 2008; 33(5):870-879. Doi: 10.1139/H08-072. 10.1249/MSS.0000000000001203. 
2619 Paulson TA, Bishop NC, Leicht CA, et al. Perceived exertion as a tool to self-regulate exercise 262 in individuals with tetraplegia. Eur J Appl Physiol 2013; 113(1):201-209. Doi:

$263 \quad 10.1007 / \mathrm{s} 00421-012-2426-5$.

26410 Amann M, Sidhu SK, Weavil JC, et al. Autonomic responses to exercise: group III/IV muscle 265 afferents and fatigue. Auton Neurosci 2015; 188:19-23. Doi: 10.1016/j.autneu.2014.10.018.

26611 Amann M, Blain GM, Proctor LT, et al. Group III and IV muscle afferents contribute to 267 ventilatory and cardiovascular response to rhythmic exercise in humans. J Appl Physiol 2010; 109(4):966-976. Doi: 10.1152/JAPPLPHYSIOL.00462.2010.

26912 Krassioukov A. Autonomic function following cervical spinal cord injury. Respir Physiol Neurobiol 2009; 169(2):157-164. Doi: 10.1016/j.resp.2009.08.003.

27113 Leicht CA, Bishop NC, Goosey-Tolfrey VL. Submaximal exercise responses in tetraplegic, paraplegic and non spinal cord injured elite wheelchair athletes. Scand J Med Sci Sports 2012; 22(6):729-736. Doi: 10.1111/j.1600-0838.2011.01328.x.

27414 West CR, Campbell IG, Goosey-Tolfrey VL, et al. Effects of abdominal binding on field-based 275 exercise responses in Paralympic athletes with cervical spinal cord injury. J Sci Med Sport 2014; 17(4):351-355. Doi: 10.1016/J.JSAMS.2013.06.001.

27715 West CR, Goosey-Tolfrey VL, Campbell IG, et al. Effect of abdominal binding on respiratory 278 mechanics during exercise in athletes with cervical spinal cord injury. J Appl Physiol 2014; 117(1):36-45. Doi: 10.1152/japplphysiol.00218.2014.

28016 Vegter RJK, Hartog J, de Groot S, et al. Early motor learning changes in upper-limb dynamics $281 \quad$ and shoulder complex loading during handrim wheelchair propulsion. J Neuroeng Rehabil 282 2015; 12(1):26. Doi: 10.1186/s12984-015-0017-5.

28317 Borg GA. Borg's Perceived Exertion and Pain Scales. Champaign, IL, Human Kinetics, 1998.

28418 Pageaux B. Perception of effort in exercise science: definition, measurement and perspectives. 
Cohen J. A power primer. Psychol Bull 1992; 112(1):155-159. Doi: 10.1037/00332909.112.1.155. Physiol Perform 2006; 1(1):50-57.

Pandolf KB, Billings DS, Drolet LL, et al. Differential ratings of perceived exertion and various physiological responses during prolonged upper and lower body exercise. Eur J Appl Physiol Occup Physiol 1984; 53(1):5-11.

Hutchinson MJ, Paulson TAW, Eston R, et al. Assessment of peak oxygen uptake during handcycling: Test-retest reliability and comparison of a ramp-incremented and perceptuallyregulated exercise test. PLoS One 2017; 12(7):e0181008. Doi: 10.1371/journal.pone.0181008.

23 Goosey-Tolfrey VL, Kirk JH. Effect of push frequency and strategy variations on economy and perceived exertion during wheelchair propulsion. Eur J Appl Physiol 2003; 90(1-2):154-158. Doi: 10.1007/s00421-003-0875-6.

24 Paulson TA, Bishop NC, Eston RG, et al. Differentiated perceived exertion and self-regulated wheelchair exercise. Arch Phys Med Rehabil 2013; 94(11):2269-2276. Doi: 10.1016/j.apmr.2013.03.018. recreationally active and trained women. J Sports Sci Med 2010; 9(4):557-563.

Bolgar MR, Baker CE, Goss FL, et al. Effect of exercise intensity on differentiated and rating of perceived exertion. Acta Physiol Scand 1971; 83(3):399-406. Doi: 10.1111/j.17481716.1971.tb05093.x. 

Med 2015; 45(11):1603-1618. Doi: 10.1007/s40279-015-0380-1.

31028 Marcora S. Perception of effort during exercise is independent of afferent feedback from 311 skeletal muscles, heart, and lungs. J Appl Physiol 2009; 106(6):2060-2062. Doi:

$312 \quad$ 10.1152/japplphysiol.90378.2008.

31329 de Morree HM, Klein C, Marcora SM. Perception of effort reflects central motor command 314 during movement execution. Psychophysiology 2012; 49(9):1242-1253. Doi: 10.1111/j.1469$315 \quad$ 8986.2012.01399.x.

31630 de Morree HM, Klein C, Marcora SM. Cortical substrates of the effects of caffeine and time317 on-task on perception of effort. J Appl Physiol 2014; 117(12):1514-1523. Doi:

$318 \quad$ 10.1152/japplphysiol.00898.2013. 
320 Table 1: Peak responses to maximal incremental wheelchair propulsion.

\begin{tabular}{lccc}
\hline & $\mathrm{AB}$ & Non-SCI & CSCI \\
\hline$\dot{\mathrm{V}} \mathrm{O}_{2 \text { peak }}\left(\mathrm{L} \cdot \mathrm{min}^{-1}\right)$ & $3.1 \pm 0.5^{* \dagger}$ & $2.4 \pm 0.7^{\dagger}$ & $1.5 \pm 0.5$ \\
$\dot{\mathrm{V}} \mathrm{O}_{\text {peak }}\left(\mathrm{ml} \cdot \mathrm{kg}^{-1} \cdot \mathrm{min}^{-1}\right)$ & $35.7 \pm 6.0^{\dagger}$ & $40.1 \pm 5.3^{\dagger}$ & $21.3 \pm 5.9$ \\
$\mathrm{HR}_{\text {peak }}\left(\right.$ beats $\left.\cdot \mathrm{min}^{-1}\right)$ & $172 \pm 18^{\dagger}$ & $188 \pm 3^{\dagger \dagger}$ & $117 \pm 11$ \\
$\mathrm{RER}_{\text {peak }}$ & $1.16 \pm 0.10^{\dagger}$ & $1.13 \pm 0.08$ & $1.01 \pm 0.06$ \\
$\dot{\mathrm{V}} E_{\text {peak }}\left(\mathrm{L} \cdot \mathrm{min}^{-1}\right)$ & $113.0 \pm 18.9^{\dagger}$ & $96.3 \pm 34.3^{\dagger}$ & $53.2 \pm 17.9$ \\
{$[\mathrm{BLa}]_{\text {peak }}\left(\mathrm{mmol} \cdot \mathrm{L}^{-1}\right)$} & $7.98 \pm 2.53^{\dagger}$ & $8.69 \pm 2.02^{\dagger}$ & $4.66 \pm 1.57$ \\
Peak speed $\left(\mathrm{m} \cdot \mathrm{s}^{-1}\right)$ & $2.7 \pm 0.4$ & $3.5 \pm 0.5^{\dagger \dagger}$ & $2.4 \pm 0.5$ \\
Time to exhaustion $(\mathrm{s})$ & $684 \pm 112^{\dagger}$ & $633 \pm 120^{\dagger}$ & $475 \pm 109$
\end{tabular}

$321 *$ : significantly greater than Non-SCI, $\uparrow:$ significantly greater than CSCI, + : significantly greater than 322 AB. 


\section{Figure captions}

324 Figure 1: Development of $\mathrm{RPE}_{\mathrm{P}}$ (solid lines) and $\mathrm{RPE}_{\mathrm{C}}$ (dashed lines) using the CR-10, relative to 325 normalised test duration (a-c) and $\dot{\mathrm{V}}_{2 \text { peak }}(\mathrm{d}-\mathrm{f})$ in $\mathrm{AB}(\mathrm{a}, \mathrm{d})$, Non-SCI (b, e) and CSCI (c, f) groups. *: $326 \quad \mathrm{RPE}_{\mathrm{P}}$ greater than $\mathrm{RPE}_{\mathrm{C}}, P<0.05$.

327 Figure 2: Effect sizes for the difference in both $\mathrm{RPE}_{\mathrm{P}}$ and $\mathrm{RPE}_{\mathrm{C}}$ from 50 to $100 \% \dot{\mathrm{V}}_{2 \text { peak }}$ between $\mathrm{AB}$,

328 Non-SCI and CSCI. Points to the right of the "Trivial" section identify instances where AB $>$ Non-

329 SCI, AB $>$ CSCI, and Non-SCI $>$ CSCI. Points to the left of the "Trivial" section identify where AB $<$

330 Non-SCI, AB $<$ CSCI, and Non-SCI $<$ CSCI. Effect sizes were categorised as trivial $(<0.2)$, small

331 (0.2-0.6), moderate (0.6-1.2), large (1.2-2.0) and very large $(>2.0)$. 

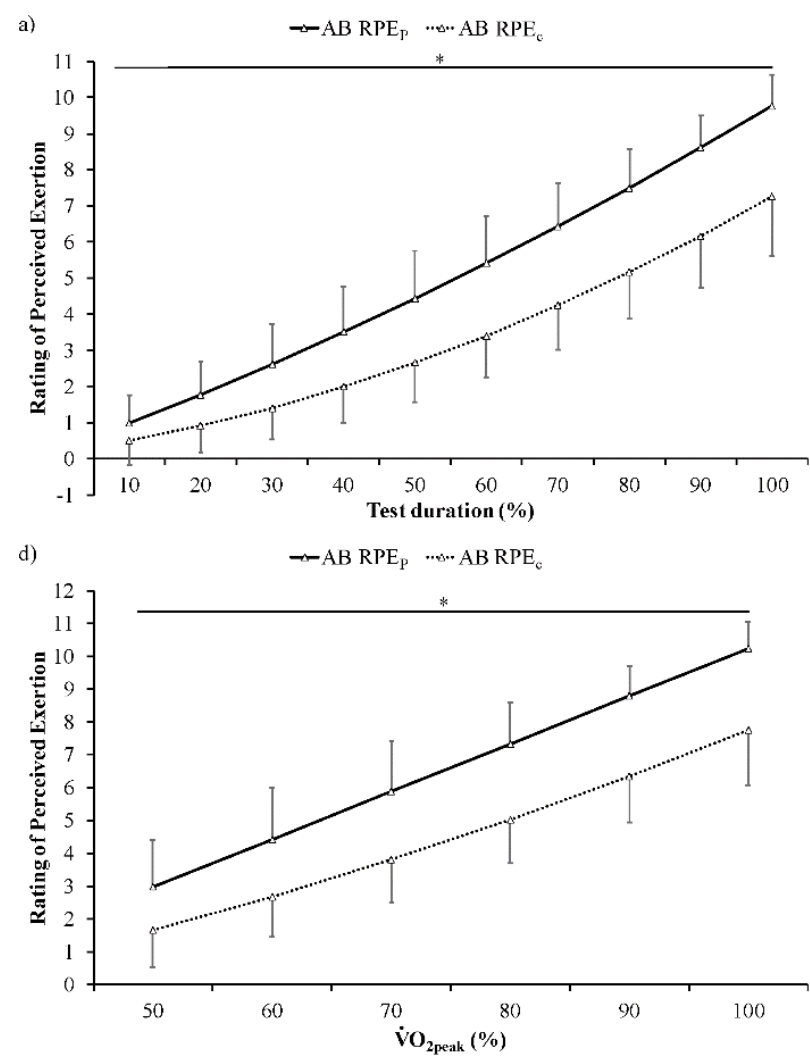
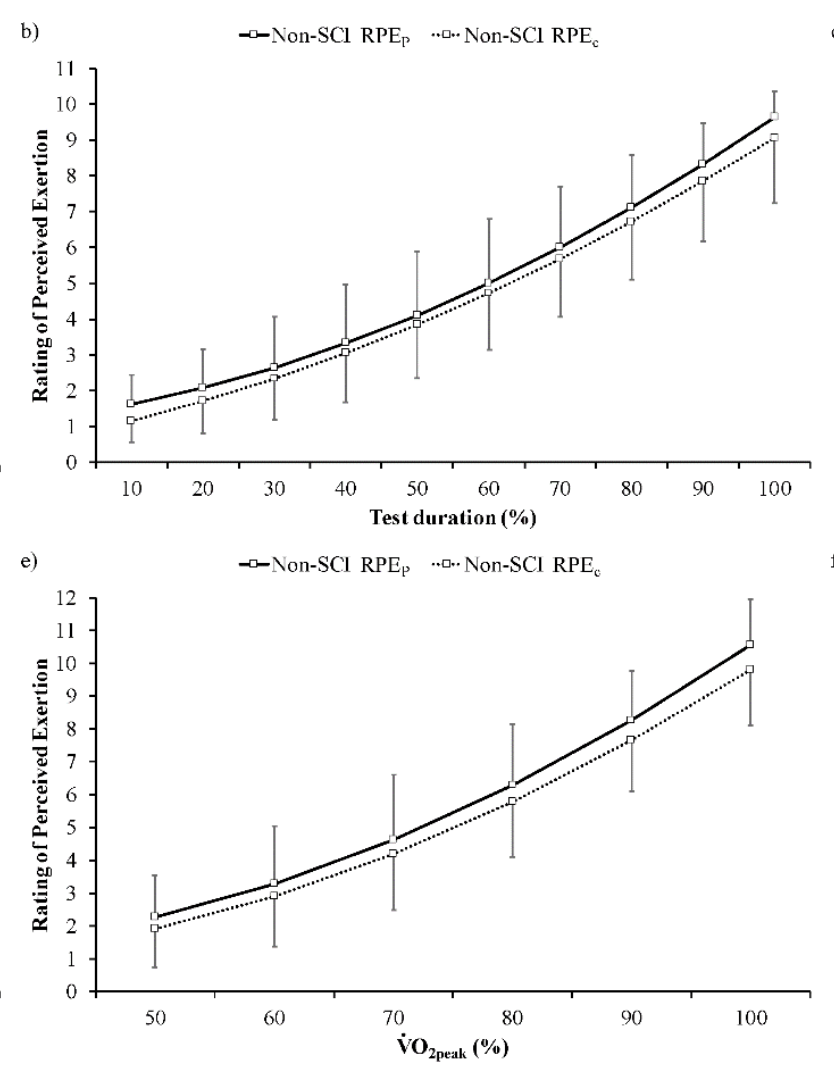
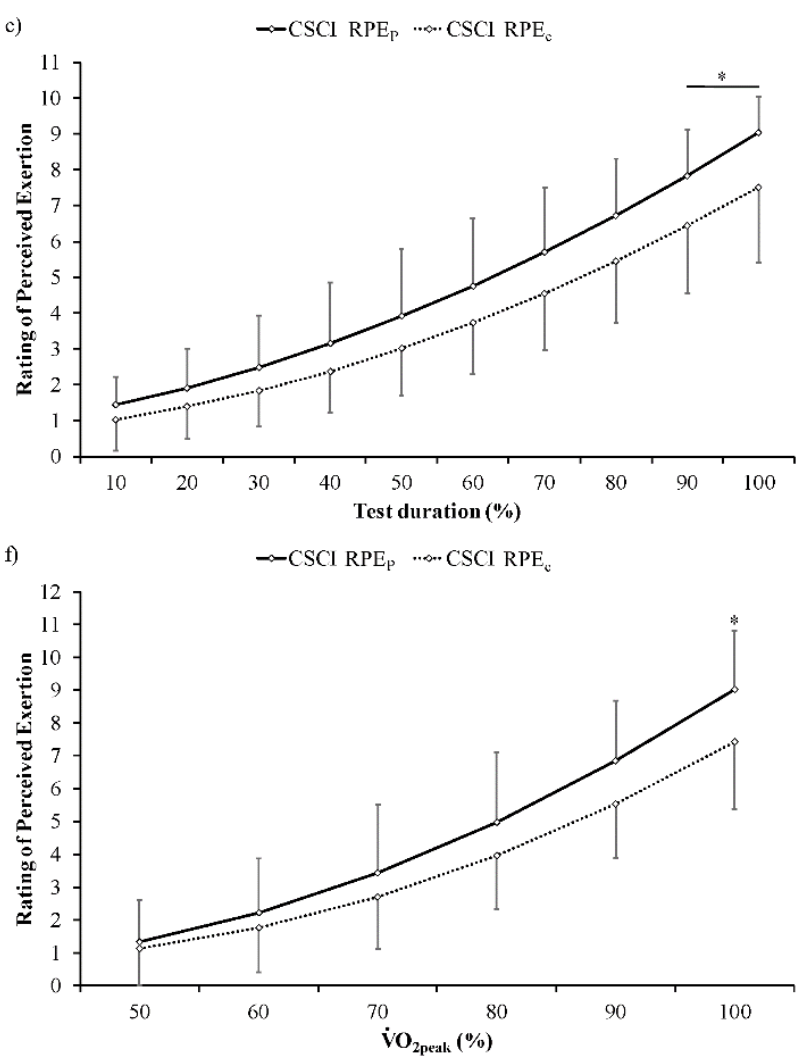
$\bullet \mathrm{AB} v$ Non-SCI $\square \mathrm{AB}$ v CSCI $\triangle$ Non-SCI v CSCI

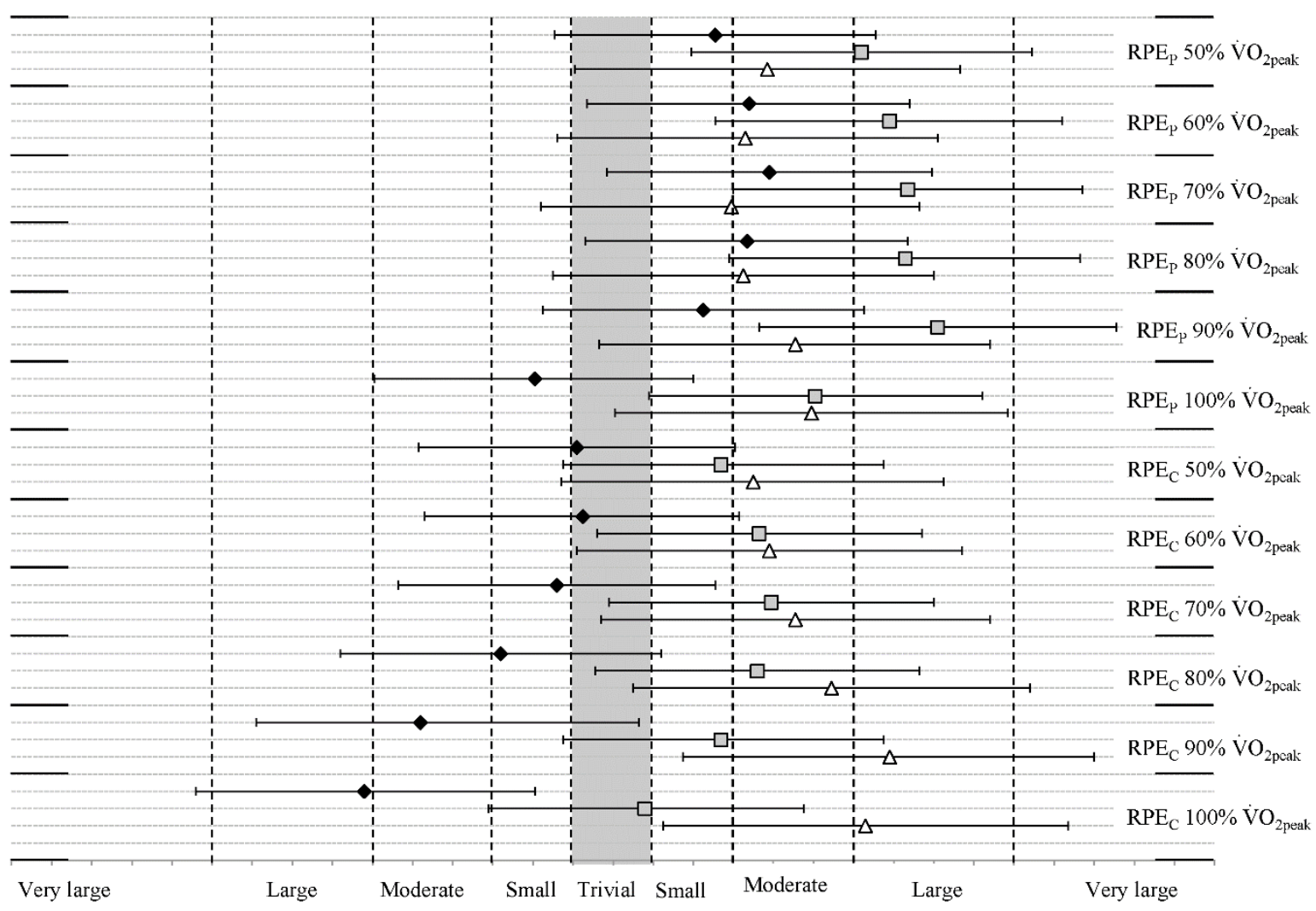

